\title{
Esophageal perforation after anterior cervical spine surgery: a systematic review of the literature
}

\author{
Sameer H. Halani, MS, Griffin R. Baum, MD, Jonathan P. Riley, MD, Gustavo Pradilla, MD, \\ Daniel Refai, MD, Gerald E. Rodts Jr., MD, and Faiz U. Ahmad, MD
}

Department of Neurological Surgery, Emory University School of Medicine, Atlanta, Georgia

\begin{abstract}
OBJECTIVE Esophageal perforation is a rare but well-known complication of anterior cervical spine surgery. The authors performed a systematic review of the literature to evaluate symptomatology, direct causes, repair methods, and associated complications of esophageal injury.

METHODS A PubMed search that adhered to the Preferred Reporting Items for Systematic Reviews and Meta-Analyses (PRISMA) guidelines included relevant clinical studies and case reports (articles written in the English language that included humans as subjects) that reported patients who underwent anterior spinal surgery and sustained some form of esophageal perforation. Available data on clinical presentation, the surgical procedure performed, outcome measures, and other individual variables were abstracted from 1980 through 2015.
\end{abstract}

RESULTS The PubMed search yielded 65 articles with 153 patients (mean age 44.7 years; range 14-85 years) who underwent anterior spinal surgery and sustained esophageal perforation, either during surgery or in a delayed fashion. The most common indications for initial anterior cervical spine surgery in these cases were vertebral fracture/dislocation $(n=77)$, spondylotic myelopathy $(n=15)$, and nucleus pulposus herniation $(n=10)$. The most commonly involved spinal levels were C5-6 $(n=51)$ and C6-7 $(n=39)$. The most common presenting symptoms included dysphagia $(n=$ $63)$, fever $(n=24)$, neck swelling $(n=23)$, and wound leakage $(n=18)$. The etiology of esophageal perforation included hardware failure $(n=31)$, hardware erosion $(n=23)$, and intraoperative injury $(n=14)$. The imaging modalities used to identify the esophageal perforations included modified contrast dye swallow studies, CT, endoscopy, plain radiography, and MRI. Esophageal repair was most commonly achieved using a modified muscle flap, as well as with primary closure. Outcomes measured in the literature were often defined by the time to oral intake following esophageal repair. Complications included pneumonia $(n=6)$, mediastinitis $(n=4)$, osteomyelitis $(n=3)$, sepsis $(n=3)$, acute respiratory distress syndrome $(n=2)$, and recurrent laryngeal nerve damage $(n=1)$. The mortality rate of esophageal perforation in the analysis was $3.92 \%$ (6 of 153 reported patients).

CONCLUSIONS Esophageal perforation after anterior cervical spine surgery is a rare complication. This systematic review demonstrates that these perforations can be stratified into 3 categories based on the timing of symptomatic onset: intraoperative, early postoperative (within 30 days of anterior spinal surgery), and delayed. The most common source of esophageal injury is hardware erosion or migration, each of which may vary in their time to symptomatic manifestation.

http://thejns.org/doi/abs/10.3171/2016.1.SPINE15898

KEY WORDS esophageal injury; ACDF; anterior cervical spine; fusion; corpectomy; discectomy; cervical

$\mathrm{A}$ NTERIOR exposure of the cervical spine has been performed safely and effectively for decades. First described by Smith, Robinson, and Cloward in $1958,{ }^{12,59}$ this approach to the intervertebral discs allowed for treatment of both central and neuroforaminal disease in the cervical spine. This technique has been refined, and by using the natural fascial planes in the neck a safe and effective exposure can be achieved in an expedient manner. While routine, this approach to the spine is not without risk. Vocal cord paralysis is a known complication caused by damage to the recurrent laryngeal nerve. ${ }^{11}$ The common carotid artery and internal jugular vein require mobilization and retraction during this approach and, while infrequent, can be damaged, requiring repair and resulting in possible neurovascular sequelae. ${ }^{9}$

A more common complication, which can go unrecognized during the initial operation, is damage to the esophagus. ${ }^{63}$ Present within the superficial layer of the deep cervical fascia, the esophagus lies dorsal to the trachea and is lined with smooth muscle. The most common complaint after an anterior approach to the cervical spine is dysphagia caused by retraction, with rates ranging from $2 \%$ to 
$67 \%$ for this transient complaint. ${ }^{6,7,24}$ A more feared complication is violation and perforation of the esophageal tissue itself. This can cause dysphagia, local soft-tissue infection, and deep infection with hardware failure, pseudarthrosis, osteomyelitis/discitis, sepsis, and-in the worst cases-infectious mediastinitis and death. ${ }^{43}$ The incidence of these complications ranges from $0.02 \%$ to $1.52 \%$, and is higher when the initial spinal injury is associated with trauma. ${ }^{1,3,13,22,44,51,68}$

Published reports of esophageal perforation are mostly in the form of case reports and small series, with no systematic reviews of the literature. Our goal is to define the rate of esophageal perforation during the anterior approach to the cervical spine, as well as expected patient presentations, causes of the perforation, types and number of repairs needed, and patient outcomes, including the inability to receive oral intake. This systematic review will help define some of these parameters.

\section{Methods \\ Study Selection}

A PubMed search that adhered to PRISMA (Preferred Reporting Items for Systematic Reviews and Meta-Analyses) was performed for all articles containing the terms "anterior cervical spine surgery" AND "esophageal," "esophagus," "complications," "esophageal injury," "dysphagia," or "esophageal perforation." For this study, articles were limited to those written in the English language where humans were defined as the subjects. The initial inclusion criteria mainly focused on patients who underwent anterior cervical spine surgery and suffered esophageal perforation directly related to surgical intervention. Patients with injury to the pharynx or hypopharynx were excluded. The anatomical definition of "esophagus" used in this review was listed according to descriptions provided per the individual reporting articles. Additionally, reports in which trauma was thought to be the cause of esophageal perforation were excluded. Case reports and series (detailing 1 or more specific patient symptoms, signs, diagnoses, treatment, and follow-up), retrospective studies (detailing more than 2 cases in a less specific and more data-based manner), and prospective analyses (following, analyzing, and documenting patients over time) were included, while editorials and commentaries were excluded. Two authors reviewed the articles, and a single screener decided which articles to include or exclude, while discrepancies or indecisions were resolved via discussion with the other authors. Individual study bias was mitigated by reviewing and confirming the appropriate indicated sources. The bibliographies of the relevant studies were manually searched to identify any additional studies. A search was also conducted on other online databases, including Google Scholar and MEDLINE, using the same criteria. Studies were limited to those published over the past 35 years (January 1, 1980, through December 7, 2015). All duplicate articles, abstracts, review articles, and letters to the editor were excluded..$^{1-5,8,10,13-18,20-23,25-58,60-62,64,65,67-75}$

Title and abstract review was performed once the initial list of studies was generated (Fig. 1). The reviewers met prior to commencing study selection to ensure consistency in the application of the inclusion criteria. Studies were selected if they met the following 3 inclusion criteria: 1) the patient underwent anterior cervical spine surgery; 2) the patient was found to have an injury to the esophagus during or after surgery; and 3) the esophageal perforation was not present before anterior cervical spine surgery.

A full-text review was performed on all remaining studies following title and abstract review. Additional studies that did not meet the inclusion criteria were excluded. The last search was performed on December 7, 2015.

\section{Data Extraction}

The literature was carefully analyzed, and data were selected based on the patient population and demographics, indications for anterior cervical spine surgery, time to diagnosis, clinical manifestations of esophageal perforation, imaging modalities used, causes of perforation, repair of perforations, complications, and clinical outcomes. The reported outcomes were time to oral intake and persistent esophageal perforation requiring additional surgery.

It is noted that not all papers provided data or information on each subset of patients, so some comparative analysis is limited due to the nature of the data. Data for all patients were reported when available in the literature. Statistical analysis was not needed for this review.

\section{Results}

\section{Study Selection}

The initial PubMed search returned 2564 studies, and 8 additional studies were identified during the bibliography search of relevant studies. A title and abstract review excluded 2465 studies, leaving 107 studies for full-text review. Following full-text review, 65 articles and 153 patients were included in our study. A flowchart of the screening process is illustrated in Fig. 1. There were 6 retrospective studies (1 of which was conducted using surveys) and 59 case reports and case series.

\section{Demographics}

The average age of our patient population (when reported in the literature) was 44.7 years $(n=120) ; 53.6 \%$ of all patients were male $(\mathrm{n}=82)$.

\section{Initial Anterior Cervical Spine Surgery}

The indications for initial anterior cervical spine surgery were reported in 106 studies, with some patients having more than 1 indication. Trauma, including fracture and dislocation of the vertebrae, was the most common $(n=77)$, followed by cervical spondylomyelopathy $(n=$ $15)$, herniated nucleus pulposus $(\mathrm{n}=10)$, degenerative disc disease $(n=8)$, malignancy $(n=6)$ ankylosing spondylitis $(n=4)$, and tuberculosis of the spine $(n=2)$. Some patients had multiple indications for surgery (Supplemental Fig. 1). Additionally, C5-6 was the most commonly operated spinal level $(\mathrm{n}=51)$, followed by C6-7 $(\mathrm{n}=39)$ (Supplemental Fig. 2). Fifty-four patients underwent anterior cervical discectomy and fusion alone, while 35 received corpectomies.

\section{Presenting Symptoms of Esophageal Perforation}

Patients often presented with multiple complaints, and 


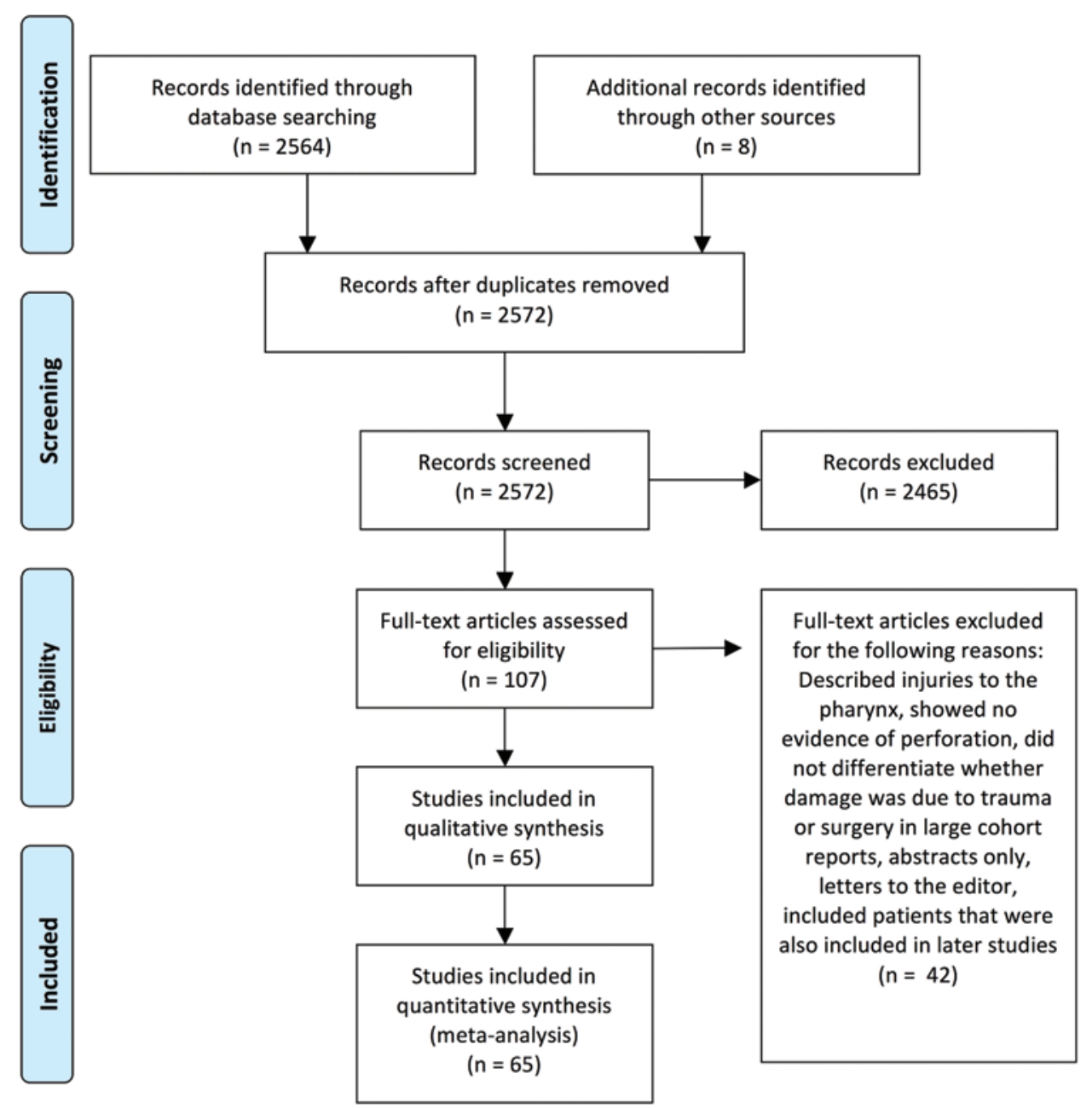

FIG. 1. PRISMA flowchart. Figure is available in color online only.

symptoms were reported in 117 patients. Most commonly, patients presented with dysphagia and odynophagia ( $\mathrm{n}=$ $63)$, followed by fever $(n=24)$, neck swelling $(n=23)$, and wound leakage $(\mathrm{n}=18)$ (Supplemental Table 1$)$.

\section{Causes of Esophageal Perforation}

The etiology of esophageal perforation was specified and reported in 75 patients. The most common cause of esophageal perforation was "hardware failure," which was responsible for $41 \%$ of perforations $(n=31)$. The literature used this term to describe plate migration $(n=5)$, screw migration $(n=11)$, and loosened plates and/or screws ( $n$ $=18$ ). Some of these occurred simultaneously. The next most common causes of perforation were chronic erosion by hardware $(n=23 ; 31 \%)$, intraoperative injury, including retraction and operative tools $(\mathrm{n}=14 ; 19 \%)$, and graft extrusion and penetration $(n=5 ; 7 \%)$ (Supplemental Table 2).

\section{Time to Diagnosis}

The time to diagnosis is defined in the literature as the time from the initial anterior cervical spine surgery to the diagnosis of esophageal perforation. The average time to diagnosis in patients in whom this parameter was reported
(121 patients) was 716.6 days, with a median of 44.5 days. The range for the time to diagnosis varied between 0 days (intraoperative injury) and 18 years.

Using an empirical cut-off value of 30 days-where fewer than 30 days is defined as early perforation and after 30 days is delayed perforation-we further stratified the time to diagnosis by the cause of esophageal perforation. Both of these results were reported in 70 patients: in this cohort, the average time to diagnosis was 983.5 days, with a median of 120 days. Thirty days was used to include the greatest number of intraoperative injuries in the "early" subgroup. The results of this stratification by time to diagnosis can be found in Fig. 2.

\section{Visualization and Imaging Modalities for Esophageal Perforation}

Multiple imaging modalities were used to identify esophageal perforation, the most common of which was a modified contrast dye swallow study $(n=66)$. These included Gastrografin, methylene blue, and barium swallow studies. Additionally, CT scanning $(n=41)$, endoscopy ( $n$ $=34)$, plain radiography $(n=16)$, and MRI $(n=3)$ were also used (Supplemental Fig. 3). 


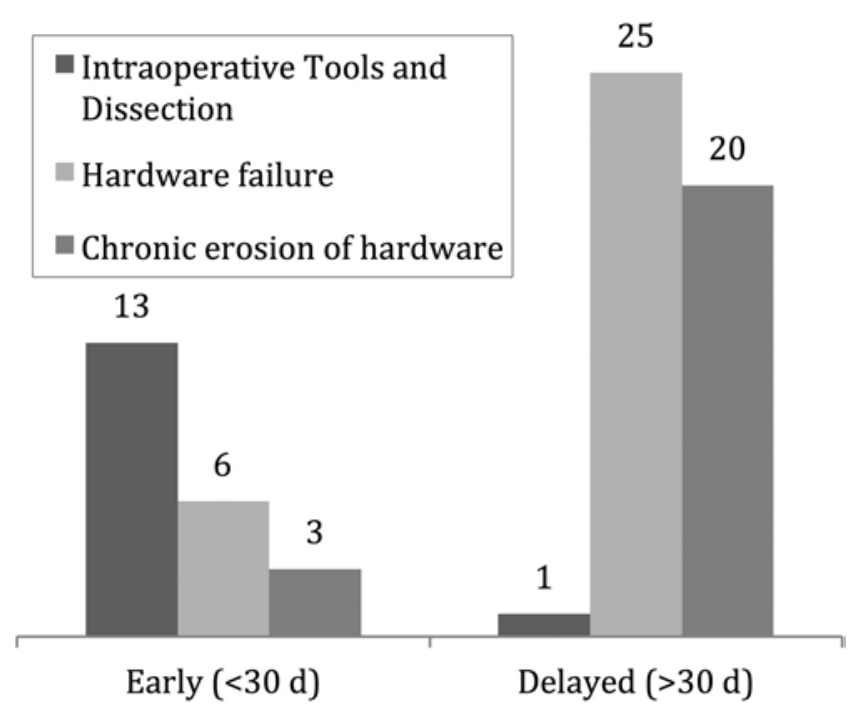

FIG. 2. Cause of esophageal perforation stratified by time to diagnosis.

\section{Esophageal Repair}

The methods of definitive esophageal repair varied and were performed mostly in conjunction with colleagues in otolaryngology or cardiothoracic surgery. The specifics of esophageal repair were reported in 96 patients: 55\% (n = 53) of patients had esophageal perforations that were repaired with a muscle flap, most commonly using the sternocleidomastoid (SCM) muscle ( $\mathrm{n}=35)$; however, other muscle flaps were also used for repair, often in conjunction with others, including the radial forearm muscle $(n=4)$, pectoralis muscle $(n=4)$, omental flaps $(n=3)$, infrahyoid muscle $(\mathrm{n}=2)$, omohyoid muscle $(\mathrm{n}=2)$, latissimus dorsi $(n=1)$, longus colli $(n=1)$, and the jejunum $(n=1)$. Time to diagnosis did not affect the method of esophageal repair used.

Primary repair comprised $34 \%$ of repairs $(n=31)$, and conservative treatment without surgical intervention was used as the treatment in $11 \%$ of patients $(\mathrm{n}=12)$. These results are summarized in Table 1.

\section{Microorganisms}

Infection, abscesses, and microbacteria were occasionally cultured at the site of esophageal perforation $(n=38)$. The most commonly found microorganisms included coagulase-positive Staphylococcus species, including methicillin-resistant Staphylococcus aureus $(\mathrm{n}=7)$, Candida species $(\mathrm{n}=7)$, Pseudomonas species $(\mathrm{n}=6)$, and Streptococcus species $(\mathrm{n}=6)$ (Supplemental Table 3$)$.

\section{Complications}

The incidence of secondary complications following esophageal repair in this study was $12.4 \%(\mathrm{n}=19)$. The most common complications were as follows: pneumonia $(n=6)$, mediastinitis $(n=4)$, osteomyelitis $(n=3)$, sepsis $(\mathrm{n}=3)$, acute respiratory distress syndrome $(\mathrm{n}=2)$, and recurrent laryngeal nerve damage $(n=1)$.

\section{Outcomes}

The outcomes measures in the literature were defined
TABLE 1. Method of definitive esophageal repair

\begin{tabular}{cc}
\hline Method of Esophageal Repair & No. of Patients \\
\hline Primary closure only & 31 \\
\hline Muscle flap & 53 \\
\hline SCM flap & 35 \\
\hline Radial forearm flap & 4 \\
\hline Pectoralis flap & 4 \\
\hline Other* & 10 \\
\hline Conservative treatment & 12 \\
\hline
\end{tabular}

* Includes jejunal, omental, longus colli, latissimus dorsi, omohyoid, and infrahyoid flaps.

by the success of the repair and the time to oral intake following repair of the esophageal perforation. This was reported in 73 patients across 34 studies. The average time to oral intake is 30.2 days, with a median of 15 days $(\mathrm{n}=$ 73 ) and range of 4 to 188 days. Further stratification of the time to oral intake by type of esophageal repair performed demonstrated that primary closure (average 28.3 days) and the use of an SCM flap (average 27.3 days) were comparable, while conservative treatment was significantly longer (average 68 days). While patients were kept off oral intake, feeding tubes were used to provide nutrition. Nutrition was provided with the assistance of a nasogastric tube $(n=51)$ and/or gastrostomy or jejunostomy tubes $(n=23)$. The type of feeding tube used did not demonstrate any significant impact on the time to oral intake.

The average number of esophageal repair attempts per patient was $1.54(\mathrm{n}=96)$. Sixty-three patients achieved closure after the first repair attempt, while 29 patients required 2 or more additional surgeries for esophageal repair before definitive closure was achieved. Of these, 21 patients achieved complete resolution of perforation only after the anterior hardware was removed. The remaining 8 patients healed without the need for the removal of anterior hardware. The mortality rate of esophageal perforation in this study was $3.92 \%$ (6 of 153 patients).

\section{Discussion}

Our goal was to define the rate of esophageal perforation during the anterior approach to the cervical spine, as well as expected patient presentations, causes of the perforation, type and number of repairs needed, and patient outcomes related to the inability to receive oral intake. The majority of patients reviewed underwent their initial anterior cervical operation because of trauma. Although iatrogenic intraoperative injury during the surgical approach was a common cause of esophageal perforation, this only represented $19 \%$ of the total perforations. Far more common was the chronic, erosive process caused by anterior instrumentation. This included failed hardware, as well as hardware that was prominent and causing mass effect and eventual erosion into the lumen of the esophagus. For this reason, health care providers must be vigilant about patients with dysphagia or odynophagia who have undergone a previous anterior cervical surgery. The average time to diagnosis was nearly 2 years, which is beyond the usual follow-up for a routine surgical patient. This poses an in- 
teresting problem, as many surgeons do not follow up with anterior cervical discectomy and fusion patients for longer than 1 year following surgery. This review sheds light on a serious complication that presents in a delayed fashion and should promote a dialogue between the surgeon and patient; having surgeons educate their patients, staff, and referring doctors about late complications would be beneficial to identifying symptoms early and preventing complications.

The causes of secondary esophageal perforation have not been studied in depth. The traditional impediments to wound healing, including preexisting infection, poor nutritional state, systemic inflammatory disease, residual postoperative fluid collection, and mass effect from the foreign hardware, can all directly contribute to the slow, erosive process that occurs over a number of years. Additionally, certain factors associated with poor healing may also be categorized as risk factors for an increased likelihood of esophageal perforation, including previous history of surgery, radiation to the neck, and extensive tobacco use. ${ }^{19}$ Once a perforation occurs, the chance of spontaneous healing is low unless the perforation is very small, as the hardware can become seeded with bacteria and poor nutritional status from dysphagia can contribute to a feedforward effect. With advances in metallurgy and implant design, several new "lower-profile" cervical plates, as well as "zero-profile" integrated implants, can reduce the mass effect upon the posterior esophagus. Further study is required to determine if this new technology can maintain an acceptable rate of fusion while minimizing rates of complications. It would be a worthwhile pursuit to explore creating a registry to identify if certain types of hardware are more frequently implicated in esophageal perforation.

When esophageal perforation does occur and reconstruction is required, the SCM flap is commonly used because of its anatomical convenience to the esophagus. The entire lateral and medial surface of the SCM muscle is exposed, while taking care to preserve the spinal accessory nerve. This portion of the SCM is used to create an inferiorly pedicled flap that is interposed between the esophagus and the spine. The distal end of the flap is tacked to the prevertebral tissue on the contralateral side to hold it in place during healing. ${ }^{44} \mathrm{~A}$ small but appreciable percentage of patients did not undergo operative management of their esophageal injury and instead received conservative management (12 patients). Our review found that the patients who had conservative treatment were younger $(8$ of these 11 patients were 34 years old or younger; overall average age 37.3 years). One may speculate that given the younger age of these patients, their wound-healing capabilities are superior to those who are older and their wounds resolved without the need for sternocleidomastoid mobilization.

It was found that primary repair with an SCM flap was the most effective method of achieving definitive esophageal repair. However, a confounding factor that often presented with repeat surgery was that the removal of hardware likely played a more pivotal role in the ultimate esophageal repair. The etiology of the initial injury helped determine the optimal method of repair. In patients who had an intraoperative injury, primary repair was often effectively used to achieve definitive repair. This was likely used because intraoperative injuries tend to be smaller, and closure can be achieved with reapproximation and oversewing of the esophagus. In patients who presented in a delayed fashion, the SCM flap was most often used. When presenting in a delayed fashion, the damage to the esophagus would likely be more extensive and would therefore require a flap as a conduit for repair.

The average number of repairs required to repair the perforation was also noteworthy from our review. For some patients, a single repair will be ineffective, demonstrating the extensive morbidity associated with this feared complication. Additionally, the amount of time that patients were receiving nothing orally can be both physically and mentally demanding. Parenteral nutrition is not without risk, including catheter-related bloodstream infection and metabolic derangements. ${ }^{66}$

This paper represents the first systematic review of the literature to examine esophageal perforation after anterior cervical spine surgery. The overall incidence is low, given the number of anterior procedures performed in a given year. This study cannot estimate the prevalence of perforations. When a perforation does occur, however, the consequences can be grave.

While informative, our study is not without limitations. The data collection was performed in a retrospective manner and is fraught with the limitations associated with that study design. Additionally, there is reporting bias, as not all cases of initial iatrogenic injury are reported and delayed perforation may not have been attributed to the surgery at diagnosis.

\section{Conclusions}

Esophageal perforation is an infrequent but serious complication of anterior cervical spinal surgery. Any patient with dysphagia after an anterior approach to the cervical spine, even years later, should receive thorough workup for a possible esophageal perforation. Further study is required to examine the future rate of chronic perforation, as new technology and lower-profile plates and screws could reduce the mass effect on the esophagus and decrease the rate of delayed perforation. Regardless, the chronic risks of this type of approach should continue to be disclosed to patients during the informed consent process before surgical intervention.

\section{References}

1. Ahn SH, Lee SH, Kim ES, Eoh W: Successful repair of esophageal perforation after anterior cervical fusion for cervical spine fracture. J Clin Neurosci 18:1374-1380, 2011

2. Almre I, Asser A, Laisaar T: Pharyngoesophageal diverticulum perforation 18 years after anterior cervical fixation. Interact Cardiovasc Thorac Surg 18:240-241, 2014

3. Amhaz HH, Kuo R, Vaidya R, Orlewicz MS: Esophageal perforation following cervical spine surgery: A review with considerations in airway management. Int J Crit Illn Inj Sci 3:276-278, 2013

4. Ardon H, Van Calenbergh F, Van Raemdonck D, Nafteux P, Depreitere B, van Loon J, et al: Oesophageal perforation after anterior cervical surgery: management in four patients. Acta Neurochir (Wien) 151:297-302, 2009

5. Balmaseda MT Jr, Pellioni DJ: Esophagocutaneous fistula in spinal cord injury: a complication of anterior cervical fusion. Arch Phys Med Rehabil 66:783-784, 1985 
6. Baron EM, Soliman AM, Gaughan JP, Simpson L, Young WF: Dysphagia, hoarseness, and unilateral true vocal fold motion impairment following anterior cervical diskectomy and fusion. Ann Otol Rhinol Laryngol 112:921-926, 2003

7. Bazaz R, Lee MJ, Yoo JU: Incidence of dysphagia after anterior cervical spine surgery: a prospective study. Spine (Phila Pa 1976) 27:2453-2458, 2002

8. Benazzo M, Spasiano R, Bertino G, Occhini A, Gatti P: Sternocleidomastoid muscle flap in esophageal perforation repair after cervical spine surgery: concepts, techniques, and personal experience. J Spinal Disord Tech 21:597-605, 2008

9. Burke JP, Gerszten PC, Welch WC: Iatrogenic vertebral artery injury during anterior cervical spine surgery. Spine J 5:508-514, 2005

10. Cagli S, Isik HS, Zileli M: Cervical screw missing secondary to delayed esophageal fistula: case report. Turk Neurosurg 19:437-440, 2009

11. Chen CC, Huang YC, Lee ST, Chen JF, Wu CT, Tu PH: Long-term result of vocal cord paralysis after anterior cervical disectomy. Eur Spine J 23:622-626, 2014

12. Cloward RB: The anterior approach for removal of ruptured cervical disks. J Neurosurg 15:602-617, 1958

13. Dakwar E, Uribe JS, Padhya TA, Vale FL: Management of delayed esophageal perforations after anterior cervical spinal surgery. J Neurosurg Spine 11:320-325, 2009

14. De Moor V, De Witte O, Zalcman M, Gelin M, Le Moine O, El Nakadi I: Oesophageal perforation by an anterior cervical fixation device: management in debilitated patients. Acta Gastroenterol Belg 68:267-269, 2005

15. Eleraky MA, Llanos C, Sonntag VK: Cervical corpectomy: report of 185 cases and review of the literature. J Neurosurg 90 (1 Suppl):35-41, 1999

16. Finiels PJ, Hernandez G, Sabatier P, Frerebeau P: Delayed esophageal perforation after cervical osteosynthesis. Case illustration. J Neurosurg 92 (1 Suppl): 123, 2000

17. Fountas KN, Kapsalaki EZ, Machinis T, Robinson JS: Extrusion of a screw into the gastrointestinal tract after anterior cervical spine plating. J Spinal Disord Tech 19:199-203, 2006

18. Fountas KN, Kapsalaki EZ, Nikolakakos LG, Smisson HF, Johnston KW, Grigorian AA, et al: Anterior cervical discectomy and fusion associated complications. Spine (Phila Pa 1976) 32:2310-2317, 2007

19. Frank J, Barker JH, Marzi I, Mutschler W: Modern therapy of chronic wounds with respect to radiation. Strahlenther Onkol 174 (Suppl 3):69-73, 1998

20. Fuji T, Kuratsu S, Shirasaki N, Harada T, Tatsumi Y, Satani M, et al: Esophagocutaneous fistula after anterior cervical spine surgery and successful treatment using a sternocleidomastoid muscle flap. A case report. Clin Orthop Relat Res (267):8-13, 1991

21. Gazzeri R, Tamorri M, Faiola A, Gazzeri G: Delayed migration of a screw into the gastrointestinal tract after anterior cervical spine plating. Spine (Phila Pa 1976) 33:E268-E271, 2008

22. Haku T, Okuda S, Kanematsu F, Oda T, Miyauchi A, Yamamoto T, et al: Repair of cervical esophageal perforation using longus colli muscle flap: a case report of a patient with cervical spinal cord injury. Spine J 8:831-835, 2008

23. Hanci M, Toprak M, Sarioğlu AC, Kaynar MY, Uzan M, Işlak C: Oesophageal perforation subsequent to anterior cervical spine screw/plate fixation. Paraplegia 33:606-609, 1995

24. Hofstetter CP, Kesavabhotla K, Boockvar JA: Zero-profile anchored spacer reduces rate of dysphagia compared with ACDF with anterior plating. J Spinal Disord Tech 28:E284E290, 2015

25. Hung CC, Guo JH, Cheng YK, Cho DY: Delayed anterior cervical screws migrating simultaneously to the lung and stomach. Spine J [epub ahead of print], 2015

26. Ji H, Liu D, You W, Zhou F, Liu Z: Success in esophageal perforation repair with open-wound management after revision cervical spine surgery: a case report. Spine (Phila Pa 1976) 40:E183-E185, 2015

27. Kau RL, Kim N, Hinni ML, Patel NP: Repair of esophageal perforation due to anterior cervical spine instrumentation. Laryngoscope 120:739-742, 2010

28. Kazi AA, Solowski NL, Postma GN, Weinberger PM: Esophageal perforation in a patient with diverticulum following anterior discectomy and fusion. Ear Nose Throat J 92:506-507, 2013

29. Kelly MF, Spiegel J, Rizzo KA, Zwillenberg D: Delayed pharyngoesophageal perforation: a complication of anterior spine surgery. Ann Otol Rhinol Laryngol 100:201-205, 1991

30. Kim YJ, Glazer PA: Delayed esophageal perforation and abscess formation after cervical vertebrectomy and fusion. Orthopedics 25:1091-1093, 2002

31. Konstantakos AK, Temes RT: Delayed esophageal perforation: a complication of anterior cervical spine fixation. Ann Thorac Surg 80:349, 2005

32. Korovessis P, Repantis T, Vitsas V, Vardakastanis K: Cervical spondylodiscitis associated with oesophageal perforation: a rare complication after anterior cervical fusion. Eur J Orthop Surg Traumatol 23 (Suppl 2):S159-S163, 2013

33. Kroepil F, Schauer M, Raffel AM, Kröpil P, Eisenberger CF, Knoefel WT: Treatment of early and delayed esophageal perforation. Indian J Surg 75:469-472, 2013

34. Küntscher MV, Erdmann D, Boltze WH, Germann G: Use of a free jejunal graft for oesophageal reconstruction following perforation after cervical spine surgery: case report and review of the literature. Spinal Cord 41:543-548, 2003

35. Kuriloff DB, Blaugrund S, Ryan J, O’Leary P: Delayed neck infection following anterior spine surgery. Laryngoscope 97:1094-1098, 1987

36. Leaver N, Colby A, Appleton N, Vimalachandran D: Oesophageal perforation caused by screw displacement 16 months following anterior cervical spine fixation. BMJ Case Rep 2015:bcr2014207738, 2015

37. Lee SH, Lee JH, Kim HJ, Chung IK, Park SH, Kim SJ: Esophageal perforation by cervical fixation device. Gastrointest Endosc 61:295, 2005

38. Lee SH, Mesfin A, Riew KD: Delayed esophageal perforation after anterior cervical fusion and retropharyngeal steroid use: a report of two cases. Spine J 15:e75-e80, 2015

39. Li Y, Zhu QS, Liu JC, Wu YT: Acute cervical epidural hematoma, screw pullout, and esophageal perforation after anterior cervical corpectomy surgery: report of a case. Int Surg 100:334-340, 2015

40. Lu DC, Theodore P, Korn WM, Chou D: Esophageal erosion 9 years after anterior cervical plate implantation. Surg Neurol 69:310-313, 2008

41. Lu X, Guo Q, Ni B: Esophagus perforation complicating anterior cervical spine surgery. Eur Spine J 21:172-177, 2012

42. Lucas J, Smith E, Eskander M, McPhee J, Lapinsky A: Esophageal perforation more than 10 years after anterior cervical spine plating. Clin Neurol Neurosurg 115:1842-1844, 2013

43. Nanda A, Sharma M, Sonig A, Ambekar S, Bollam P: Surgical complications of anterior cervical diskectomy and fusion for cervical degenerative disk disease: a single surgeon's experience of 1,576 patients. World Neurosurg 82:1380-1387, 2014

44. Navarro R, Javahery R, Eismont F, Arnold DJ, Bhatia NN, Vanni S, et al: The role of the sternocleidomastoid muscle flap for esophageal fistula repair in anterior cervical spine surgery. Spine (Phila Pa 1976) 30:E617-E622, 2005

45. Newhouse KE, Lindsey RW, Clark CR, Lieponis J, Murphy MJ: Esophageal perforation following anterior cervical spine surgery. Spine (Phila Pa 1976) 14:1051-1053, 1989

46. Ning X, Wen Y, Xiao-Jian Y, Bin N, De-Yu C, Jian-Ru X, et al: Anterior cervical locking plate-related complications; 
prevention and treatment recommendations. Int Orthop 32:649-655, 2008

47. Nourbakhsh A, Garges KJ: Esophageal perforation with a locking screw: a case report and review of the literature. Spine (Phila Pa 1976) 32:E428-E435, 2007

48. Okawa A, Yoshida H, Haro H, Shinomiya K: Esophageal invagination to a graft after cervical corpectomy. Case illustration. J Neurosurg 96 (1 Suppl): 136, 2002

49. Orlando ER, Caroli E, Ferrante L: Management of the cervical esophagus and hypofarinx perforations complicating anterior cervical spine surgery. Spine (Phila Pa 1976) 28:E290-E295, 2003

50. Patel NP, Wolcott WP, Johnson JP, Cambron H, Lewin M, McBride D, et al: Esophageal injury associated with anterior cervical spine surgery. Surg Neurol 69:20-24, 24, 2008

51. Phommachanh V, Patil YJ, McCaffrey TV, Vale F, Freeman TB, Padhya TA: Otolaryngologic management of delayed pharyngoesophageal perforation following anterior cervical spine surgery. Laryngoscope 120:930-936, 2010

52. Pichler W, Maier A, Rappl T, Clement HG, Grechenig W: Delayed hypopharyngeal and esophageal perforation after anterior spinal fusion: primary repair reinforced by pedicled pectoralis major flap. Spine (Phila Pa 1976) 31:E268-E270, 2006

53. Reid RR, Dutra J, Conley DB, Ondra SL, Dumanian GA: Improved repair of cervical esophageal fistula complicating anterior spinal fusion: free omental flap compared with pectoralis major flap. Report of four cases. J Neurosurg 100 (1 Suppl Spine):66-70, 2004

54. Rubin JS: Sternocleidomastoid myoplasty for the repair of chronic cervical esophageal fistulae. Laryngoscope 96:834836,1986

55. Rueth N, Shaw D, Groth S, Stranberg S, D'Cunha J, Sembrano J, et al: Management of cervical esophageal injury after spinal surgery. Ann Thorac Surg 90:1128-1133, 2010

56. Sahjpaul RL: Esophageal perforation from anterior cervical screw migration. Surg Neurol 68:205-210, 2007

57. Sansur CA, Early S, Reibel J, Arlet V: Pharyngocutaneous fistula after anterior cervical spine surgery. Eur Spine J 18:586-591, 2009

58. Shenoy SN, Raja A: Delayed pharyngo-esophageal perforation: rare complication of anterior cervical spine surgery. Neurol India 51:534-536, 2003

59. Smith GW, Robinson RA: The treatment of certain cervicalspine disorders by anterior removal of the intervertebral disc and interbody fusion. J Bone Joint Surg Am 40-A:607-624, 1958

60. Smith MD, Bolesta MJ: Esophageal perforation after anterior cervical plate fixation: a report of two cases. J Spinal Disord 5:357-362, 1992

61. Solerio D, Ruffini E, Gargiulo G, Camandona M, Raggio E, Solini A, et al: Successful surgical management of a delayed pharyngo-esophageal perforation after anterior cervical spine plating. Eur Spine J 17 (Suppl 2):S280-S284, 2008

62. Sun L, Song YM, Liu LM, Gong Q, Liu H, Li T, et al: Causes, treatment and prevention of esophageal fistulas in anterior cervical spine surgery. Orthop Surg 4:241-246, 2012

63. Tew JM Jr, Mayfield FH: Complications of surgery of the anterior cervical spine. Clin Neurosurg 23:424-434, 1976

64. Thomas JP, Finch R: Esophageal erosion. A complication of acrylic fixation in anterior cervical fusion. Spine (Phila Pa 1976) 16:1238-1240, 1991

65. Tian H, Yuan W, Johnson JS, Chen H, Chen D: Pharyngoesophageal diverticulum: a delayed complication of anterior cervical spine surgery. Eur Spine J 20 (Suppl 2):S211-S216, 2011

66. Turpin RS, Solem C, Pontes-Arruda A, Sanon M, Mehta $\mathrm{S}$, Xiaoqing Liu F, et al: The impact of parenteral nutrition preparation on bloodstream infection risk and costs. Eur J Clin Nutr 68:953-958, 2014
67. van Berge Henegouwen DP, Roukema JA, de Nie JC, vd Werken C: Esophageal perforation during surgery on the cervical spine. Neurosurgery 29:766-768, 1991

68. von Rahden BH, Stein HJ, Scherer MA: Late hypopharyngoesophageal perforation after cervical spine surgery: proposal of a therapeutic strategy. Eur Spine J 14:880-886, 2005

69. Vrouenraets BC, Been HD, Brouwer-Mladin R, Bruno M, van Lanschot JJ: Esophageal perforation associated with cervical spine surgery: report of two cases and review of the literature. Dig Surg 21:246-249, 2004

70. Whitehill R, Sirna EC, Young DC, Cantrell RW: Late esophageal perforation from an autogenous bone graft. Report of a case. J Bone Joint Surg Am 67:644-645, 1985

71. Wierzbicka M, Bartochowska A, Banaszewski J, Szyfter W: Cervical oesophageal and hypopharyngeal perforations after anterior cervical spine surgery salvaged with regional and free flaps. Neurol Neurochir Pol 47:43-48, 2013

72. Witwer BP, Resnick DK: Delayed esophageal injury without instrumentation failure: complication of anterior cervical instrumentation. J Spinal Disord Tech 16:519-523, 2003

73. Zairi F, Tetard MC, Thines L, Assaker R: Management of delayed oesophagus perforation and osteomyelitis after cervical spine surgery: review of the literature. Br J Neurosurg 26:185-188, 2012

74. Zdichavsky M, Blauth M, Bosch U, Rosenthal H, Knop C, Bastian L: Late esophageal perforation complicating anterior cervical plate fixation in ankylosing spondylitis: a case report and review of the literature. Arch Orthop Trauma Surg 124:349-353, 2004

75. Zhong ZM, Jiang JM, Qu DB, Wang J, Li XP, Lu KW, et al: Esophageal perforation related to anterior cervical spinal surgery. J Clin Neurosci 20:1402-1405, 2013

\section{Disclosures}

Dr. Ahmad is a consultant for Depuy-Synthes. Dr. Rodts is a consultant for Medtronic and Globus Medical.

\section{Author Contributions}

Conception and design: Ahmad, Halani. Acquisition of data: Halani. Analysis and interpretation of data: all authors. Drafting the article: all authors. Critically revising the article: all authors. Reviewed submitted version of manuscript: all authors. Approved the final version of the manuscript on behalf of all authors: Ahmad. Statistical analysis: Halani. Administrative/technical/ material support: Ahmad.

\section{Supplemental Information \\ Online-Only Content}

Supplemental material is available with the online version of the article.

Supplemental Material. http://thejns.org/doi/suppl/10.3171/ 2016.1.SPINE15898.

\section{Previous Presentations}

Portions of this work were presented as a platform presentation at the Annual Spring Meeting of the Georgia Neurosurgical Society at Sea Island, Georgia, on May 22-24, 2015, and the Joint Section on Disorders of the Spine and Peripheral Nerves Summit in Orlando, Florida, on March 16-19, 2016.

\section{Correspondence}

Faiz Ahmad, Department of Neurological Surgery, Emory University School of Medicine, 49 Jesse Hill Dr. SE, Rm. 341, Atlanta, GA 30303. email: faiz.ahmad@emory.edu. 